\title{
O Livro de Rute: uma leitura sobre o discurso e as relações de poder
}

\author{
The Book of Ruth: \\ a reading about discourse and power relations
}

Cláudia Andréa Prata Ferreira ${ }^{I}$

\section{Resumo}

Os rituais da festividade de Shavuot e sua relação com o Livro de Rute reúnem três elementos fundamentais sobre as questões sociais e uma tríplice categoria protegida por Deus: Rute é uma mulher e uma mulher estrangeira, pobre e viúva. Sua figura acaba tornando-se uma espécie de memória que liga a libertação do cativeiro egípcio a uma legislação de cunho social para proteger os pobres e excluídos (Deuteronômio). Este estudo examina as relações entre discurso e poder no livro de Rute. De tal forma, procuramos evidenciar a realidade e o significado da experiência feminina e as questões sociais que o livro reflete. Alguns importantes conceitos são relembrados tais como as leis que tratam de questões sociais que se referem ao pobre, ao estrangeiro, aos órfãos

\footnotetext{
${ }^{1}$ A perspectiva do presente trabalho é o texto bíblico, a sua narrativa, sua elaboração e transmissão como elemento que forja uma identidade e memória (coletiva) na Tradição Judaica. Observamos um longo e complexo processo de composição e transmissão das histórias (bíblicas) e a tentativa de harmonizar ao longo do tempo as aparentes contradições e discrepâncias do que ficou conhecido como a narrativa bíblica. Não ignoramos as contribuições dos estudos historiográficos e arqueológicos, mas nosso foco é sobre a narrativa. Nossas considerações estão, portanto, delimitadas ao aspecto literário do texto hebraico bíblico atual. Para efeito didático e de simplificação adotamos o termos judeu e judaico não fazendo a distinção entre os termos usados de acordo com a periodização histórica.
} 
e viúvas, trabalhadores, atitudes de tolerância e benevolência (Lv 19,9-10; 23,22 e Dt 24,20-22). A narrativa de Rute torna-se, portanto, uma espécie de resgate da legislação social que objetiva reestabelecer procedimentos justos para com a camada social menos favorecida.

Palavras-chave: Livro de Rute, Relações sociais, Relações de poder, Estudos Judaicos.

\begin{abstract}
The Shavuot Festival Rituals and its relation with The Ruth Book bring together three key elements about social issues and a threefold category protected by God: Ruth is woman, a foreigner woman, poor and widow. Her character becomes a sort of memory that connect the departure of the enslavement under the Egyptians to a social nature legislation to protect the poor and excluded (Deuteronomy). This research examines the relations between discourse and power in Book of Ruth. Thus, we seek to put in evidence the reality and the meaning of gender experience related to women and social issues showed in that book. Some important concepts are remembered such as laws that deal with poor related social issues, tolerance attitudes and benevolence (Lv 19,9-10; 23,22 e Dt 24,20-22). Ruth's narrative becomes, therefore, a sort of recovering of social laws that aim to re-establish fair procedures to less-favoured social groups.
\end{abstract}

Keywords: Book of Ruth, Social Relations, Power Relations, Jewish Studies.

\title{
Introdução
}

O ato de lembrar no judaísmo torna-se imperativo, pois é ele que garante através da perpetuação da memória que os acontecimentos fundamentais e constitutivos para a formação desse grupo (o judaico) e do pacto com Deus não se percam na memória dos filhos de Israel.

Não se trata mais de um grupo de famílias divididas pelas origens das tribos ou de uma revelação individual que passa de pai para filho por fidelidade ao clã, ao patriarca. A lembrança da saída do Egito é fundamental para a compreensão do nascimento do povo e da própria religião. A saída do Egito marca o início do povo judeu como um grupo organizado e regido por suas 
próprias leis, reveladas ao povo por Moisés, sete semanas após a saída do cativeiro egípcio. Podemos inferir que muitas das leis presentes no texto bíblico tenham sido criadas sob o impacto do efeito do cativeiro egípcio sobre o povo judaico. Encontramos um número expressivo de leis que tratam de questões sociais que se referem ao pobre, ao estrangeiro, aos órfãos e viúvas, trabalhadores, atitudes de tolerância e benevolência, nos quais a lembrança do cativeiro egípcio é frequentemente mencionada através de um leitmotiv que funciona como um imperativo de lembrança "E lembrarás que servo foste na terra do Egito" (Dt 5,15) e que perpassa o texto bíblico em diversas passagens. Essa lembrança justifica todas as orientações da legislação social com o intuito de estabelecer procedimentos justos para com os menos favorecidos.

\section{Memória Judaica e Shalosh Regalim}

A memória judaica não se encontra restrita à narrativa. Manter a memória restrita ao âmbito da narrativa poderia fazer com que a mesma ficasse paralisada no tempo e sem sentido para as gerações futuras. A memória judaica ganha sentido e realidade somente quando, através da repetição do ritual, o tempo histórico é destruído e podemos experenciar de novo o tempo verdadeiro das origens, o tempo originário. Na festividade de Pessach (Páscoa Judaica) reproduzimos a cada ano a experiência da saída do cativeiro egípcio, a libertação, em que cada indivíduo judeu refaz a sua história como se ele próprio tivesse saído do Egito. ${ }^{2} \mathrm{O}$ relato dessa saída é vivencial e se destina a todos, não se pretende que as pessoas tenham uma aquisição intelectual do fato, ao contrário, o objetivo é a repetição simbólica da experiência original, que auxilia a compreensão de um fato passado e simultaneamente um fato presente na vida de cada um que revive essa experiência.

\footnotetext{
${ }^{2}$ Originalmente, a Páscoa judaica era constituída de dois feriados distintos: Chag HaPessach, a Festa do Cordeiro Pascal, e Chag Hamatzot, a Festa dos Pães Ázimos, observados muito antes da experiência judaica no cativeiro egípcio. Nos tempos antigos, quando a maioria dos hebreus vivia no deserto como pastores nômades, as famílias "judaicas” celebravam a chegada da primavera oferecendo um sacrifício (Pessach, o cordeiro pascal). Posteriormente, foi instituído um outro feriado na primavera, de caráter agrícola: Chag Hamatzot, quando os lavradores comemoravam o início da colheita de trigo desfazendo-se de toda massa fermentada. Com o tempo, estas duas festas associaram-se a outro evento que ocorreu na primavera: o Êxodo do Egito. Chag HaPessach foi identificado com o fato de Deus ter "passado por cima" (passach em hebraico) das casas dos israelitas, poupando-os da décima praga, a morte dos primogênitos egípcios. Por outro lado, Chag Hamatzot foi relacionado com o fato de que os judeus, em sua fuga apressada do Egito, não tiveram tempo de esperar a massa crescer, e assaram pães ázimos com a massa não fermentada.
} 
A memória judaica foi essencialmente preservada pela transmissão oral e pela tradição como um mandamento coletivo conforme observamos nas passagens do livro de Deuteronômio (Dt 5,15; 6,20-24; 25,17-19; 26,16; 32,7).

O conteúdo da memória judaica foi primeiramente a saga coletiva tal como registrada na fonte bíblica e posteriormente, em coletividade, os rituais rememorando esses acontecimentos. O significado central do passado bíblico é o pacto, o pacto da memória ${ }^{3}$, a garantia de que Israel seguirá através da história o plano divino. A memória judaica é essencialmente um reconhecimento de Deus, do pacto e de sua revelação por intermédio da Torá (Pentateuco), memória fundadora da identidade judaica. A lealdade para com Deus, parte constitutiva do pacto da memória, que tirou seu povo do cativeiro egípcio, se torna elemento constitutivo de Israel. A Torá, além de ser dom divino, aparece como tarefa do povo, pois o povo vivenciando seus ensinamentos preserva o sentido da existência e faz com que estes ensinamentos sejam um zikaron "lembrança", "memória" do que foi, é e será. ${ }^{4}$ No texto bíblico, a lembrança é fundamental. O verbo hebraico lizkór "lembrar"s aparece em várias declinações tendo como tema Israel ou Deus, uma vez que ambos estão ligados pelo Pacto da Memória.

\footnotetext{
${ }^{3}$ Ressaltamos que a expressão Pacto da Memória é uma criação nossa para designar a ideia de um pacto contínuo que perpassa todo o texto bíblico. É a aliança feita por Deus desde os Patriarcas e que vai sendo renovada através dos tempos. Obs. Desenvolvemos o conceito de Pacto da Memória na tese de doutoramento, ano de defesa 2002 (v. referências bibliográficas).

${ }^{4} \mathrm{Na}$ documentação bíblica, a palavra hebraica zikaron significa "lembrança", "memória", "recordação"; e, na fonte moderna, "memória". A raiz verbal hebraica $z k r$ ( $z$ chr) significa "fazer menção", "mencionar", "lembrar", "lembrar-se", "haver menção de”, "existir lembrança de", "ser mencionado", "ser imputado", "trazer à memória", "tornar-se conhecido", "anunciar", "confessar" e "louvar". A raiz hebraica para designar memória é composta pelas letras $z k r(z c h r)$. Essa raiz se faz presente na literatura e na liturgia para nos recordar o dever da lembrança. A aliança é um zikaron. O zikaron celebra a promessa mútua de memória entre Deus e Israel, o pacto da memória através dos tempos. O zikaron dirige-se a Deus, convidado a "lembrar-se" quer do povo que executa o rito, quer do gesto salvador que cumpriu outrora e cuja renovação permanente se impõe (Gn 8,1; 9,15; 19,29; 30,22; Ex 6,5; 28,12.29; 30,16; 39,7; Lv 2,2-9.16; 5,12.26; 6,8; 24,7; Nm 5,15.18; 17,5; 31,54; Sl 10,11; 13,2; Zc 6,14; Ml 3,16). O zikaron dirige-se igualmente ao povo que deve lembrar-se do gesto de Deus e de seu significado permanente (Ex 12,14; 13,9; 17,14; Lv 23,2; Nm 10,10; Dt 2,9; 8,11.14.18-19; 9,7; 24,17-19; 32,7; Js 4,6; Ecl 1,11; 2,16; Is 44,21). ${ }^{5}$ YERUSHALMI, Yosef Hayim. Zakhor: história judaica e memória judaica. Rio de Janeiro: Imago, 1992. p.25: “... o verbo zakhar aparece na Bíblia, em suas várias declinações nada menos do que 169 vezes, geralmente tendo como tema Israel ou Deus, uma vez que a memória está a serviço de ambos. O verbo é complementado pela sua contrapartida - esquecer. Assim como Israel é ordenado a lembrar, também é intimado a não esquecer".
} 
A festividade de Pessach é o primeiro dos shalosh regalim, os três festivais de peregrinação (Pessach, Shavuot e Sucot), datas máximas do calendário judaico bíblico, quando os judeus convergiam para Jerusalém, para celebrar e trazer as oferendas ao Templo. Pessach celebra a libertação do Povo Judeu da escravidão egípcia; Shavuot, a Revelação Divina no Monte Sinai e o recebimento da Torá - o principal propósito da saída do Egito; e, Sucot, a proteção Divina com a qual foi agraciada a geração de judeus que foi libertada do Egito após os 40 anos em que percorreu o Deserto do Sinai. Na segunda noite de Pessach, iniciamos a Sefirát HaOmer ${ }^{6}$, contando 49 dias entre Pessach e Shavuot, dia em que a Torá foi outorgada ao povo de Israel. Esta contagem foi ordenada por Deus e serve como preparação ao povo para o recebimento da Torá. A palavra hebraica sefirá basicamente significa cálculo ou contagem. ${ }^{7}$ Pode-se considerar, portanto, Shavuot, de certa forma, como a conclusão da festa de Pessach. Seu próprio nome, que significa "Semanas", evidencia a ligação entre ambas.

\section{Shavuot}

A festividade de Shavuot é vista como o feriado que lembra o dia em que Deus deu ao povo judeu a Torá (Pentateuco), logo após a descida de Moisés do Monte Sinai. Contudo, na Torá não há referências que o feriado de Shavuot é de qualquer maneira relacionado com Matan Torá (a outorga da Torá). Na Bíblia, Shavuot é estritamente um festival agrícola, que marcava a transição entre a colheita de cevada - que era trazida ao sacerdote no Templo de Jerusalém em 16 de Nisan (Pessach cai em 14 de Nisan) - e o começo da época de amadurecimento do trigo, que começava na primeira semana do mês de Sivan. A Torá se refere à Shavuot por várias expressões: 1) como Chag haKatzir, a festa da colheita (Ex. 23,14-19); 2) como Chag haShavuot, o festival das semanas (Nm. 28,26); e 3) como Iom haBikurim, o dia dos primeiros frutos, das primícias, quando os lavradores traziam seus produtos ao Templo, como oferenda (Lv 23,9-22). Portanto, sempre significados agrícolas.

\footnotetext{
${ }^{6}$ Sefirat Ha'Omer, a contagem de sete semanas entre os dois feriados, nos lembra simbolicamente que, de acordo com o pensamento judaico, o que importa não é libertar-se de alguma coisa, mas libertar-se para alguma coisa. A liberdade não tem sentido se não for acompanhada do compromisso para com um ideal.

${ }^{7}$ O período que separa Pessach de Shavuot (sete semanas) é o período para que o grupo (judaico) se prepare para o recebimento da Torá. No grupo cristão é o período de Ascensão que separa a Páscoa cristã de sua próxima data, Pentecostes (a festa de Shavuot ressignificada), que no contexto cristão é a comemoração da descida do Espírito Santo sobre os Apóstolos.
} 
A festividade de Shavuot foi ressignificada após e em consequência da destruição do Segundo Templo (ano 70 E.C.). ${ }^{8}$ Ocorreu uma transformação notável no caráter do festival. Com base no versículo "No terceiro mês de saírem os filhos de Israel da terra do Egito, neste dia chegaram ao deserto do Sinai" (Ex 19,1), o festival tornou-se o aniversário da outorga da Torá (zman matan torateinu, "o tempo da doação de nossa Torá"). A festividade perdeu seu caráter primariamente agrícola e de festa de peregrinação ao Templo para receber um novo significado, uma nova dimensão, a dimensão espiritual.

Como observa Kirschbaum (2003) $)^{9}$, o espessamento do novo significado da festividade de Shavuot foi intenso, para compensar a inexistência de cerimônias bíblicas conectadas com a outorga da Torá. Assim foram criadas: a introdução do tikun leil Shavuot ${ }^{10}$ e a leitura do livro de Rute.

Observamos algumas razões para a leitura do Livro de Rute na festividade de Shavuot: 1) O Livro de Rute descreve detalhadamente a beleza da época da colheita, que coincide com Shavuot - resgate de seu caráter agrícola. Os judeus podem estar espalhados em várias comunidades pelo mundo, mas a liturgia, as festas judaicas e a leitura do livro de Rute fortalecem os laços que os ligam a esta terra especial. 2) No Livro de Rute alguns importantes conceitos são relembrados tais como as leis que tratam de questões sociais que se referem ao pobre, ao estrangeiro, aos órfãos e viúvas, trabalhadores,

\footnotetext{
${ }^{8}$ Citação de datas: Segue a tendência internacional para pesquisas de culturas não cristãs: a.E.C. $($ antes da Era Comum $)=$ a.C. $($ antes de Cristo $)$ e E.C. $($ Era Comum $)=$ d.C. $($ depois de Cristo $)$. ${ }^{9}$ KIRSCHBAUM, Saul. Sobre o caráter diacrônico dos festivais religiosos. São Paulo: REVER, /2003/. Fórum. Revista de Estudos da Religião. Pós-graduação em Ciência da Religião da PUC-SP.

${ }^{10}$ De acordo com o Midrash ("Interpretação"), na noite anterior à entrega da Torá no Monte Sinai, os israelitas adormeceram e tiveram que ser acordados por Moisés com trovões e relâmpagos. Para compensar o desrespeito, indiferença e insensibilidade dos "nossos" antepassados, para reparar aquela afronta a Deus, passamos a noite em claro, estudando, demonstrando assim que estamos plenamente conscientes da importância do evento e aguardamos com grande expectativa a Revelação. O costume tem o nome de tikun leil Shavuot, literalmente "o aprimoramento da noite de Shavuot". Os mais observantes passam a noite inteira estudando trechos dos livros sagrados - Tanach (Bíblia Hebraica), Mishná ("Aquilo que se repete" - leis, debates e explicações sobre as Mitzvot da Torá e os versículos do Tanach), Talmud ("Aquilo que se ensina" - acréscimos, explicações e debates sobre o que consta na Mishná), Zohar ("Esplendor”, uma das obras mais conhecidas e influentes da Cabalá) - lendo poemas litúrgicos e recitando orações. Nas comunidades mais liberais, realiza-se um Lernen de Shavuot, uma sessão de estudos ou uma discussão em grupo sobre um tema judaico de interesse geral. Obs.: Midrash é uma palavra cunhada na última época bíblica. No período rabínico toma o sentido preciso de "interpretação e exposição" livre e imaginosa do texto bíblico.
} 
atitudes de tolerância e benevolência (Lv 19,9-10; 23,22 e Dt 24,20-22). Desta forma, podemos afirmar que o livro de Rute reaviva tal como o relato do cativeiro egípcio, uma preocupação com os "direitos humanos" e as "questões sociais" no "grupo judaico". ${ }^{11}$ Torna-se, portanto, uma espécie de resgate da legislação social que objetiva reestabelecer procedimentos justos para com a camada social menos favorecida.

\section{Contextualizando o Livro de Rute}

O Livro de Rute apresenta uma história ambientada no tempo dos juízes, mas os seus escritos são antagônicos aos de Juízes. Na realidade, o Livro de Rute data da época pós-exílica, mais provavelmente do período persa (séculos VI-V a.E.C.). A Tradição Judaica atribui a autoria do livro de Rute a Samuel, mas na realidade a autoria é desconhecida. A maioria dos estudiosos concorda que o redator é um deuteronomista. O perfil dos redatores deuteronomistas: a reafirmação dos valores deuteronomísticos, abandonados pelos deportados e sacerdotes, que incluíam a proteção à viúva, ao estrangeiro e ao órfão, além de reafirmar "Iavé" como único Deus, valores que contestavam o tributarismo, por tantas vezes impostos pelas várias monarquias. Os livros de Esdras e Neemias constituem as principais documentações bíblicas para o estudo do quadro histórico deste período: as reformas de Esdras (Esd 7,10; 7,12-22; 9,2; $10,15)$ e a crise agrária e as reformas de Neemias (Ne 5,1-5; 5,7-13; 5,14-15). Outra documentação de suporte são os textos dos profetas Ageu e Zacarias. O livro de Rute seria de certa forma uma resposta às reformas iniciadas por Esdras e Neemias e um convite ao leitor a uma análise mais crítica do panorama histórico, socioeconômico e religioso.

O que chama justamente a atenção sobre o texto é a personagem reunir três elementos fundamentais sobre as questões sociais e uma tríplice categoria protegida por Deus: ela é uma mulher e uma mulher estrangeira, pobre e viúva. Rute acaba tornando-se uma espécie de memória que liga a libertação do cativeiro egípcio a uma legislação de cunho social para proteger os pobres e excluídos (Deuteronômio). Na terra de Israel, as espigas ou os feixes de espigas, os frutos, as uvas e as azeitonas deixados nos campos após a colheita eram destinados ao órfão, à viúva e ao estrangeiro, que assim tinham algo para poder comer (Lv 19,9-10 e Dt 24,19). O proprietário não tinha o direito

${ }_{11}$ Tomamos a liberdade do uso do anacronismo para melhor compreensão das ideias que pretendemos desenvolver no presente trabalho. 
de raspar suas terras a ponto de nada deixar para os necessitados. ${ }^{12}$ A terra de Israel era considerada propriedade exclusiva de Deus $(\operatorname{Lv} 25,23)^{13}$. Diante de tal contexto, cada "proprietário de terra" deve se lembrar de que o solo não lhe pertence de todo, Deus empresta o solo. ${ }^{14} \mathrm{O}$ "proprietário" tem direito a usufruir de seu trabalho, mas os pobres devem poder também servir-se do solo para alimentar-se em caso de necessidade. ${ }^{15}$

No Livro de Rute, os pobres já não podiam catar os restos da colheita, a menos que os donos dos campos o permitissem (Rt 2,2). O que era um direito transforma-se em um favor. Rute, estrangeira, viúva e pobre, para poder alimentar a si e a sua sogra idosa, igualmente, viúva e pobre, depende de caridade; afinal ela é menos que uma serva; por isso, ela se considera como uma "estrangeira", "estranha" sem a proteção da lei (Rt 2,10). Rute vai aos campos respigar e acaba no campo pertencente à Boaz, que é da família de Elimelech (Rt 2,3), o marido falecido de Naomi, a sogra de Rute (Cf. Rt 2,2; 2,6-9; 2,15-16.). Boaz permite que Rute respigue em seu campo, recomenda que não faça isso em outros campos, não saia dali e fique junto de suas servas. Boaz recomenda aos seus servos que

\footnotetext{
${ }_{12}$ Alguns conceitos importantes constam no texto bíblico para compreensão do quadro com a preocupação dos "direitos humanos" e "justiça social”. Cf.: WOLPO, Shalom Dov. Conceitos judaicos. São Paulo: Lubavitch - Brasil/Yeshivá Tomchei Temimim Lubavitch, 2010. p.92. Leket: Uma ou duas espigas que caíram da mão durante a ceifa não devem ser recolhidas, e sim deixadas para que os pobres as recolham. Shichechá: Quem esqueceu as espigas ou feixes de espigas no campo durante a colheita, não pode voltar para pegá-los e sim deixar para os pobres. A mesma lei é válida para os pomares e vinhedos. Peá: O dono da terra ao colher no seu campo não deve ceifá-lo todo, e sim deixar um pouco de colheita nas extremidades para os necessitados. A peá também deve ser deixada nos pomares e vinhedos. Peret e Olelot: Peret é uma uva ou duas que desprendem-se de um cacho na hora da colheita. Olelot são cachos pequenos, cujas uvas são separadas. Deve-se deixar tanto o peret quanto os olelot no vinhedo, sem colhê-los, para que sejam colhidos pelos pobres. Ver Lv 19,9-10; Dt 24,19-21.

${ }^{13}$ Cf. Js 22,19; Sl 85,2; Os 9,3; Jr 16,18; Ez 35,5.

${ }^{14}$ Outro importante conceito presente no texto bíblico é a Shemitá. A shemitá ocorre a cada sete anos na Terra de Israel. Durante este ano sabático, a Terra de Israel não pode ser cultivada. Quando se inicia este sétimo ano, todos os empréstimos e dívidas são cancelados. Além disso, todos eram obrigados a emprestar ao necessitado, dinheiro e alimentos sem juros. E também toda a safra agrícola, que cresce naturalmente, não podendo ter sido cultivada, pertence aos pobres, aos estrangeiros e aos animais domesticados. A Shemitá lembra ao povo judeu que toda a terra, na realidade, pertence a Deus e não ao homem. Cf. Lv 25,2-10; 25,20-22.35-40; Dt 15,1-2. ${ }^{15}$ Cf. Zc 7,9-10: Deus defende a viúva, o órfão, o migrante e o pobre. Sobre a causa da viúva e do órfão: Ex 22,21; Dt 24,21-22; Is 1,17.23; 9,16; Jr 7,6; 22,3; Ez 22,7; Sl 82,3; Zc 7,9. Sobre a causa do estrangeiro ou migrante: Ex 22,20; 23,9; Lv 19,10; 25,35; Dt 15,11; Am 2,6; 5,12; 8,6; Is 3,15; 10,$13 ; 11,4 ; Z c 7,10$. Sobre a causa do pobre: Ex 22,24; 23,11; Lv 19,10; 25,35; Dt 15,11; Am 2,6; 5,12 ; 8,6 ; Is 3,$15 ; 10,13 ; 11,4 ; Z c 7,10$.
} 
Rute colhesse as espigas do seu campo sem que fosse embaraçada, constrangida. Se Boaz era um parente próximo, não caberia a ele proteger Naomi sem que ela dependesse de Rute para sobreviver, ter o que comer? Afinal, Boaz toma tais atitudes de proteção apenas por conta do parentesco com Naomi e sensibilizado pela dedicação de Rute à sogra ou havia algum tipo de constrangimento causado aos pobres nos campos ou até mesmo uma violência e abusos em relação às mulheres? Ou ambos os motivos provocam a reação de Boaz?

Boaz reconforta Rute e a convida a comer junto com os segadores, isso equivalia a estabelecer laços duradouros (Rt 2,14-17), e é então que Naomi se dá conta de que Boaz é alguém (parente próximo e pode ser um resgatador, goel) que pode resgatá-las (Rt 2,20). ${ }^{16}$ No contexto do Livro de Rute, a lei do resgate $^{17}$ tem estreita ligação com a lei do levirato ${ }^{18}$, que concerne diretamente a Naomi e Rute.

A situação de Naomi é grave, pois viúva de Elimelech, ela também perdeu seus dois filhos, que não deixaram descendência. A amizade e solidariedade entre Naomi e Rute fazem com que mudem de tática na luta pela sobrevivência. Já não é mais a luta para respigar e garantir o alimento na época da colheita, mas traçar planos para o futuro, o foco passa a ser a situação da família (Rt $3,1)$. Naomi traça um plano e Rute segue as suas orientações, pois Naomi tem como ideia levar Boaz a cumprir a lei do resgate (Rt 3,2-6). Afinal, Boaz é o parente que deve cumprir o que manda a lei (Rt 3,8-9). Naomi se inspirou na história de Tamar, a esposa do filho mais velho de Judá (Gn 38,1-26) que, ao ficar viúva, se disfarça de prostituta para obrigar seu sogro a cumprir a lei

\footnotetext{
${ }^{16}$ Sendo da família de Elimelech (marido de Naomi), Boaz poderia ser considerado um redentor/resgatador, ou seja, alguém que preserva a propriedade de um parente empobrecido (ver Lv 25,29).

${ }^{17}$ A lei do resgate estabelecia dois pontos principais: 1) Se alguém, por motivo de empobrecimento, fosse obrigado a vender a sua terra, então o parente mais rico tinha a obrigação de "resgatá-la". Ou seja, ele devia comprá-la não para si mesmo, mas para dá-la ao parente pobre impossibilitado de fazê-lo (Lv 25,23-25). 2) Se alguém, por motivo de empobrecimento, via-se obrigado a vender-se a si mesmo como escravo, o parente mais próximo tinha a obrigação de "resgatá-lo". Ou seja, ele devia pagar a soma necessária para que seu irmão recobrasse a liberdade (Lv 25,47-49). Esse parente próximo era chamado de "resgatador" (em hebraico, goel). O objetivo da lei do resgate era de defender e fortalecer a família no sentido amplo. A lei também impedia que um pequeno grupo acumulasse propriedades à custa dos mais pobres e impedia que as pessoas pobres viessem a perder a sua liberdade, tornando-se escravos de pessoas com maiores recursos.

${ }^{18}$ A lei do levirato (Dt 25,5-10) estabelecia que se um homem casado morresse sem ter filhos, um de seus irmãos devia casar-se com a viúva, e o primogênito de tal união seria legalmente considerado como filho do falecido. O objetivo é o de perpetuar a descendência masculina, "o nome", garantindo assim a continuidade da família e impedir que o patrimônio passe para as mãos de outros. Ver também a história de Tamar (Gn 38,1-26).
} 
do levirato. Naomi instrui Rute a convencer Boaz a cumprir a lei do resgate. Rute, assim como Tamar, se prepara, enfeita-se, vai ao celeiro do campo de Boaz e espera Boaz dormir, para a execução do plano (Rt 3,4-7). Neste ponto da narrativa fica a dúvida: Rute quer que Boaz cumpra a lei do levirato ou a lei do resgate? Como Boaz exercerá o direito de resgate? A lei do resgate não obriga ninguém a se casar (ver $\mathrm{Ne} 5,8-11$ ). Boaz cumprirá a lei do levirato (família) ou a lei do resgate (terra)? Na narrativa, os dois assuntos estão misturados e intrinsecamente ligados. Na passagem Rt 4,5-8 observamos a afirmação de que só adquire o direito de resgatar a terra de Naomi, aquele que aceitar casar-se com Rute. O tema sobre o resgate é recorrente - foi mencionado no segundo capítulo (Rt 2,15-23), como assunto central e também no terceiro capítulo, durante a conversa entre Boaz e Rute (Rt 3,8-13). As palavras que predominam na narrativa são "resgatar" e "resgatar o nome", o que demonstra onde está centralizado o interesse da perícope Rt 4,1-12.

No breve diálogo entre Boaz e Rute, Rute não pede um favor, mas apela para o direito que a lei lhe concede. Boaz compreendeu o sentido das palavras de Rute (Rt 3,8-13). ${ }^{19}$ Observamos ao longo da narrativa como Rute, a viúva, estrangeira e pobre cresce na consideração dos que a cercam. Inicialmente, ela foi acolhida por Naomi, sua sogra (Rt 1,18), posteriormente ela foi recebida como filha de Abraão por Boaz (Rt 2,11-12); e finalmente, com a união com Boaz, agora é "toda a porta do meu povo" ${ }^{20}$ (Rt 4,11), que vê nela "uma mulher de valor", título que também é dado a Boaz e aos juízes de Israel (Rt 2,1; Jz 6,12;11,1).

\footnotetext{
${ }^{19}$ Quando um homem falece sem deixar filhos, seu irmão deve desposar a viúva, para através de seus filhos preservar seu nome. Este costume era conhecido como "casamento por levirato". Embora Boaz não fosse irmão de Machlon (falecido marido de Rute e filho de Naomi), deveria também preservar seu nome, casando com a viúva, caso aceitasse ser seu redentor/resgatador. Boaz reconhece que há outro parente que poderia ser o redentor e o convoca para uma conversa no portão da cidade na presença de dez homens entre os anciões da cidade como testemunhas, para que afirme se aceita ou não assumir esta responsabilidade, lembrando que uma resposta afirmativa acarretaria também a obrigação de casar com Rute, a viúva de Machlon. O parente aceitou comprar o campo (lei do resgate), mas quando foi colocada a questão de que ao comprar o campo de Naomi e da viúva Rute, ela também deveria ser redimida para preservar o nome e a herança do falecido (lei do levirato) a resposta foi negativa. Como este parente não aceitou ser o redentor, Boaz ficou livre para assumir esta função. Observação: O menino que nascer será o herdeiro legal de Machlon (o falecido marido de Rute) e de Elimelech (falecido marido de Naomi) e é a ele que pertencerá o terreno. Donde, a razão provável da recusa do primeiro goel que temia com isso sofrer prejuízos na negociação. Como Naomi não tem mais idade para gerar filhos, apenas Rute fica como alvo da lei do levirato.

${ }^{20}$ A porta (ou portão) da cidade é o lugar onde o povo se reúne para tratar das questões do seu cotidiano (temas sociais, administrativos, comerciais e até mesmo religiosos).
} 


\section{Conclusão}

Não podemos finalizar uma abordagem do Livro de Rute sem considerar sua costura final das questões sociais abordadas com a ideia do Messias. É da casa de David que sairá o Messias, o Redentor de Israel. No período do Talmud já estava consolidado no judaísmo a ideia de um Messias descendente de David. A narrativa cita explicitamente, ao final, David como descendente de Rute (Rt 4,18-21). Constatamos então, por intermédio da genealogia apresentada, que não apenas uma mulher pagã (Rute), mas sim duas (Tamar e Rute) são ancestrais do rei David. Quando os rabinos do período talmúdico incluem história de Rute no cânone judaico e a louvam como a prosélita ideal (Dt 10,19), afirmam que a genética não é o fator primordial no judaísmo, mas sim a crença e a prática dos mandamentos.

Na Tradição Cristã, o Messias também sairá da Casa de David, Jesus é descendente da Casa de David. Em Mateus 1,1-21 narra a genealogia desde Abraão até o nascimento de Jesus e fica claro que José "pai de Jesus" é descendente da Casa de David. A tradição cristã recebe uma leitura da tradição judaica e ressignifica-a para sua perspectiva. Contudo, algumas questões surgem a respeito: a genealogia de Davi fazia parte da obra original ou é um acréscimo posterior usado para "canonizar" o livro? Ou a existência de um "davidismo" forte entre os judaítas que elogiam Belém em contraste com Jerusalém, pois os reis (de Jerusalém) levaram Judá ao exílio, enquanto Davi (de Belém) "unificou" as tribos dispersas e formou um "país"? Há realmente este "davidismo" no pós-exílio? O livro de Rute seria como uma defesa da restauração da dinastia davídica no pós-exílio? Seguimos na direção de que a narrativa de Rute tem uma redação e perfil deuteronomista e a reafirmação dos valores deuteronomísticos conforme mencionamos na contextualização do livro. O livro de Rute, além de resgatar e reafirmar os valores deuteronomísticos tem uma ligação com três festividades judaicas relacionadas ao Êxodo - Pessach, Shavuot e Sucot - apesar de ocorrerem em meses diferentes do calendário judaico, estão relacionadas ao Exxodo. Os festivais de peregrinação (Shalosh Regalim: Pessach, Shavuot e Sucot) dramatizam de modo impressionante o pacto de Israel com Deus e reafirmam o próprio papel de cada judeu dentro desta sociedade. Um dos temas igualmente constante é o respeito ao estrangeiro fazendo Israel lembrar-se que foi estrangeiro e cativo na terra do Egito e sua libertação foi uma ação de Deus. Portanto, o Livro de Rute une temas e preocupações presentes e constantes nas três festas (Pessach, Shavuot e Sucot) sobre os "direitos humanos" e 
as "questões sociais". Rute, a estrangeira, é a imagem de uma mulher corajosa do tempo pós-exílico, que colabora na construção de Israel, mas não de um Israel e de um judaísmo organizados e centralizados em torno do Templo, de monarquias e de leis excludentes. O Livro de Rute resgata as leis que garantem os direitos dos pobres e abrem uma perspectiva para a inclusão das mulheres estrangeiras. Nesse contexto, a genealogia ligando Rute a Davi e, consequentemente, ao Messias é uma poderosa mensagem de dimensões social, política e religiosa da inclusão dos estrangeiros na comunidade de Israel, como também das ideias universalistas abordadas pelo Segundo Isaías (40-55), em Malaquias e no Terceiro Isaías (56-66).

\section{Referências Bibliográficas}

ABADIE, Phillipe. O livro de Esdras e Neemias. São Paulo: Paulus, 1998.

ALANATI, Leonardo. Releituras rabínicas do livro de Rute. Estudos Bíblicos 98 (2008/2) 72-76. Petrópolis: Vozes.

ARAÚJO, Gilvan Leite de. História da festa judaica das Tendas. São Paulo: Paulinas, 2011.

BONDER, Nilton. Pessach: um manual. Rio de Janeiro: Imago, 1990.

. Rosh Ha-Shaná e Iom Kipur: dias intensos. Rio de Janeiro: Imago, 1990.

BÍBLIA Sagrada de Jerusalém, A (BSJ). s.ed. São Paulo: Paulinas, 1991.

BRENNER, Athalya (org.). Rute a partir de uma leitura de gênero. São Paulo: Paulinas, 2002.

DICHI, Isaac. Regras gramaticais do Lachon Hacodesh. In: . Vaani Tefilá:

Leis referentes às orações. Resumo prático baseados nos livros de Halachá. São Paulo: Congregação Mekor Haim, 1992. p.160-181.

FERNANDES, Leonardo Agostini. Rute. São Paulo: Paulinas, 2012.

FERREIRA, Cláudia Andréa Prata. O pacto da memória: interpretação e identidade nas fontes bíblica e talmúdica. Tese de Doutorado em Ciência da Literatura (Poética). Rio de Janeiro: UFRJ/Faculdade de Letras, 2002.

. O Seder de Pessach: Memória, Rito e Mito no Judaísmo. In: LESSA, Fábio de Souza e BUSTAMANTE, Regina Maria da Cunha (orgs.). Memória \& Festa. Rio de Janeiro: Mauad, 2005. p.21-27. 
FRIZZO, Antonio Carlos. A Trilogia Social: estrangeiro, órfão e viúva no Deuteronômio e sua recepção na Mishná. Tese de doutorado em Teologia. Rio de Janeiro: PUC-Rio/Departamento de Teologia, 2009.

HARRIS, R. Laird et alii. Dicionário internacional de teologia do Antigo Testamento. São Paulo, Vida Nova, 1998.

KIRSCHBAUM, Saul. Sobre o caráter diacrônico dos festivais religiosos. São Paulo: REVER, /2003/. Fórum. Revista de Estudos da Religião. Pós-graduação em Ciência da Religião da PUC-SP. Disponível em: $<$ http://www.pucsp.br/rever/relatori/kirschbaum01.htm>. Acesso em 08 de maio de 2004.

KITZINGER, Ângela Maringoli. Messianismo - de Rute ao Brasil Contemporâneo: Sofrimento e Esperança - Rute 4,1-12. Dissertação de mestrado em Ciências da Religião. São Bernardo do Campo, São Paulo: UMESP/Faculdade de Filosofia e Ciências da Religião, 2011.

KOLATCH, Alfred J. Livro judaico dos porquês. São Paulo: Sefer, 1996. V.1. KRAMER, Pedro. Origem e legislação do Deuteronômio: programa de uma sociedade sem empobrecidos e excluídos. São Paulo: Paulinas, 2002.

LOPES, Mercedes. O livro de Rute. Ribla 52 (2005/3) 88-100. Petrópolis: Vozes.

MAIMÔNIDES (Maimon), Moisés. Sefer Hamitsvót do Rambam (613 Mandamentos). Reordenado de acordo com o Mishnê Torá. Rio de Janeiro: Beit Lubavitch, 2012.

MESTERS, Carlos. Rute. Petrópolis: Vozes, 1987.

. Como ler o livro de Ruth: pão, família, terra. São Paulo: Vozes, 1991.

MONLOUBOU, L. et alii. A eucaristia na Bíblia. São Paulo: Paulinas, 1985.

SCARDELAI, Donizete. O escriba Esdras e o Judaísmo: um estudo sobre Esdras na tradição judaica. São Paulo: Paulus, 2012.

SILVA, Aldina. Rute: um evangelho para a mulher de hoje. São Paulo: Paulinas, 2002.

SILVA, Airton José da. Leitura do livro de Rute: algumas dificuldades. Observatório Bíblico. São Paulo, Brasil: Blogspot. Disponível em: $<$ http://blog.airtonjo.com/2008/01/leitura-do-livro-de-rute-algumas. html $>$. Acesso em 15 de janeiro de 2008. 
STEINMETZ, Avraham. O Guia. Fundamentos Judaicos para iniciantes. São Paulo: Chabad, 1996.

STORNIOLO, Ivo. Como ler o Livro de Deuteronômio. Escolher a vida ou a morte. $5^{\text {a }}$ ed. São Paulo: Paulus, 2007.

TORÁ. A Lei de Moisés. Edição revisada e ampliada da obra A Lei de Moisés (de Meir Matzliach Melamed) e as Haftarót. Inclui a tradução das Cinco Meguilot por David Gorodovits e Ruben Najmanovich. São Paulo: Sefer, 2001.

WOLPO, Shalom Dov. Conceitos judaicos. São Paulo: Lubavitch - Brasil/ Yeshivá Tomchei Temimim Lubavitch, 2012.

YERUSHALMI, Yosef Hayim. Zakhor: história judaica e memória judaica. Rio de Janeiro: Imago, 1992.

\section{Cláudia Andréa Prata Ferreira}

Doutora em Ciência da Literatura - Poética (FL/UFRJ) Mestre em Ciência da Literatura - Teoria da Literatura (FL/UFRJ)

Professora no Departamento de Letras Orientais e Eslavas (Setor de Língua e Literatura Hebraica) da Faculdade de Letras/UFRJ Brasil

E-mail: chadileh@gmail.com

Recebido em 01/06/13

Aprovado em 18/11/13 